\title{
A taphonomic approach to marine abrasion on human bones
}

\begin{abstract}
Coastal areas are often scenes of various phenomena linked to forensic cases, such as homicides, suicides, naval accidents linked to clandestine migration, or simply coastal sites with human remains that are affected by aquatic phenomena. It is in this context where the Taphonomy can contribute to responding to many problems within the forensic field. Our goal is to determine the morphology, density and orientation of the changes caused by the action of marine sediments on the surface of a human femur. The use of binocular loupe, have enabled a more detailed analysis of abrasion. It has been determined that abrasion traces are distributed across all surface of the bone and presented an anisotropic spatial orientation, i.e. present a non-random pattern. The results have been used to corroborate on a human bone subjected to natural phenomena, the observations carried out in the experimental field by others authors.
\end{abstract}

Keywords: forensic taphonomy, marine abrasion on human bone, spatial distribution of abrasion traces
Volume 5 Issue 3 - 2017

\begin{abstract}
Atilio Nasti
Facultad de Medicina, Unidad de Medicina Legal, Pontificia Universidad Catolica Argentina Santa Maria de los Buenos Aires, Argentina

Correspondence: Atilio Nasti, Facultad de Medicina, Unidad de Medicina Legal, Pontificia Universidad Catolica Argentina Santa Maria de los Buenos Aires, (U.C.A), Avenida Alicia Moreau de Justo I500, CI I07AFB CABA, Buenos Aires, Argentina, Email atilioaasti@gmail.com
\end{abstract}

Received: June 27, 2017| Published: August 15, 2017

\section{Introduction}

The coastal shorelines are frequent scenarios of various events related to forensic cases, such as homicides, suicides, naval accidents related to clandestine migrations, dragging and transport of human remains by rivers or even onshore areas affected by aquatic events, by sea and other natural disasters. ${ }^{1,2}$ Keeping in mind the evidence drawn from the human skeleton is where the taphonomy can contribute for answering many questions within the forensic field. ${ }^{3-5}$ The taphonomy, an adaptation of a discipline that originated in palaeontology, has grown in recent years in forensic field. Specifically it has found a role in assisting investigations in assessing the post-mortem interval (PMI) and ascertaining whether remains have been disturbed and redeposited. ${ }^{4}$ Within the taphonomical studies, many of the efforts have been concentrated in the understanding of the processes that affect the disintegration, dragging, transport, dispersion, and other post mortem alterations on human remains and in which way this alterations can be interpreted within the forensic context. ${ }^{6-11}$ The development of this perspective has provoked a conceptual change in forensic anthropology in the last twenty years, giving rise to an important interaction between the theoretical and methodological aspects that have been crucial for the progress in this discipline, progress that is summarized in the perception of how forensic anthropology must be approached under a new paradigm. ${ }^{12}$

Since the last two decades, field and experimental studies, have attempted a multivariate analysis to understand the way in which the environmental factors affect the skeletal remains providing interesting conclusions about the phenomena that affect the bones as time passes by, especially in vertebrates skeletons in fresh air. ${ }^{13-24}$ Within the environmental factors, a significant effort has been done to understand the interaction between the skeletal remains and the sedimentary context ${ }^{16,25-32}$ among others. Nevertheless, and in spite of such efforts, our understanding about the effects on submerged bones, is extremely limited. ${ }^{5,33}$ An absolute understanding of these changes would be very valuable for generating an initial interpretation of the taphonomical history within the forensic context, although, still, it is not very clear the relationship between the taphonomical phenomena generated in immersion contexts, in one hand and the skeletal profile expected on the other hand. ${ }^{7-9,34}$

This work has as an objective identifying and describing the post mortem alteration produced by the transportation of non-consolidated marine sediments over the surface of a human femur. The possibility to examine a human skeletal specimen subject to marine sedimentary abrasion in natural and non-experimental contexts, should not be despised. Although we can only jump to some conclusions about the behavior of the marine sedimentary abrasion over the surface of a human bone, specially the collection of regularities in the morphology as the spatial orientation pattern of the prints encourages the utilization of those results in order to deduce the taphonomical profile of one human femur. At the same time it would be representative of the phenomena of marine abrasion in other large bones of the human skeleton. The conclusions of these observations are compatible with those obtained by other authors through experimental studies, which encourages in the future the gathering of an expected model for the marine abrasion in forensic contexts. ${ }^{9,35}$

\section{Posing of the problem}

The marine and fluvial sediments that affect the bones producing their abrasion are some of the less known phenomena within the taphonomical studies. Identifying, and quantifying the alterations to macro and microscopic levels are decisive at the time of determining the time in which the bone was submerged, the way of transportation and other taphonomical history that are used to determine, among other things, the post mortem range. ${ }^{1}$ These investigations have demonstrated that the quantity and way of the alterations would be related with the type of bone, integrity state of the bone, age, ontological characteristics, duration of exposition to the environment, type of sediment and the energy produced by the liquid medium of transportation, among other attributes. ${ }^{5,9,36}$ When a skeleton enters 
the water it is subject to a certain quantity of physical, chemical and biological processes that are capable of greatly modifying the skeletal remains. ${ }^{12}$ The phenomena that acts over the human bones are poorly understood and that is because, among other factors, the low frequency of counting for the observation of human skeletal remains that have been subject to the action of the marine environment., ${ }^{8}, 10$ In consequence for its nature, the human skeletal remains involved in these contexts, cannot be easily studied because they do not appear,because of to the disintegration, dispersion and destruction of the skeletal remains. ${ }^{18,21,23,36}$

\section{Materials and methodology}

The specimen under study is a diaphysis of a right human femur of a length of $290 \mathrm{~mm}, 29,67 \mathrm{~mm}$ of diameter and 173,5 grams of weight. It does not have any of its epiphysis, so it is very difficult to assign sex and age. It was found in January of 2013 in the coast of a beach of the Island of Florianopolis, State of Santa Catarina, Brazil, (Figure 1). The specimen showed was half-buried in the sand at three meters from the limit of low tide from the line of the coast. There were investigations around the area, in order to locate more human remains, but it seems the exemplary was isolated. The area of the discovery does not present records of archeological sites or areas of historical cemeteries close to the coast. The integrity of the bone structure of the diaphysis, its weight and the absence of fissure lines or other alterations of the periosteal surface (stage 1) in the weathering scale of Behrensmeyer, ${ }^{16}$ makes us assume that, from a chronological point of view, we would be talking about a current bone(Figure 2).

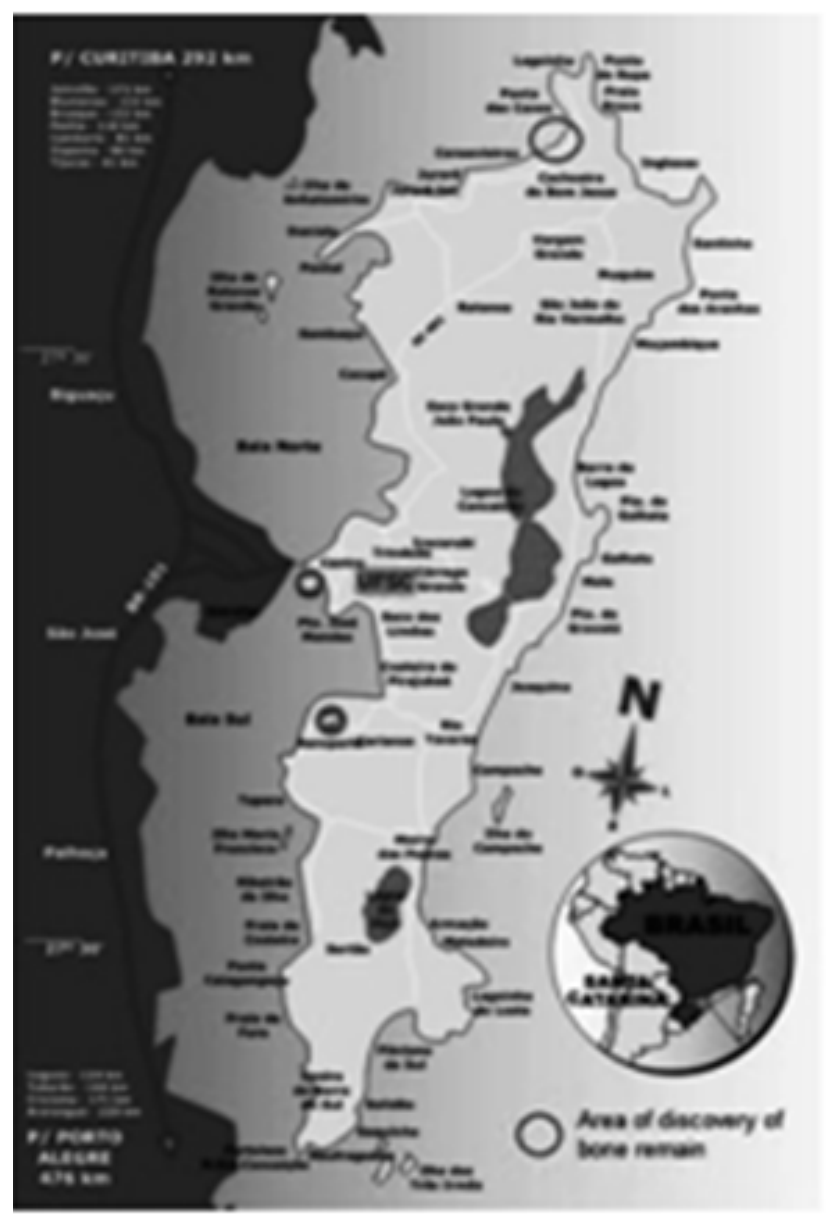

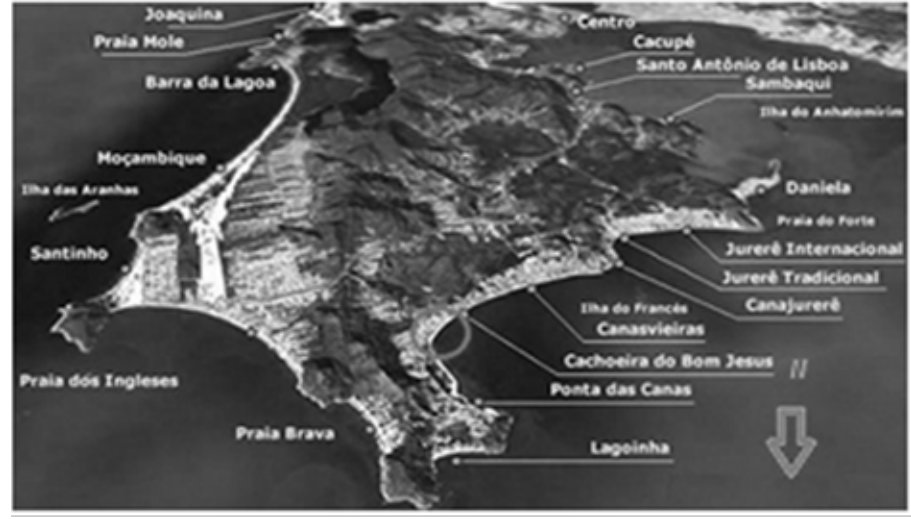

Figure I Maps showing the area of discovery.

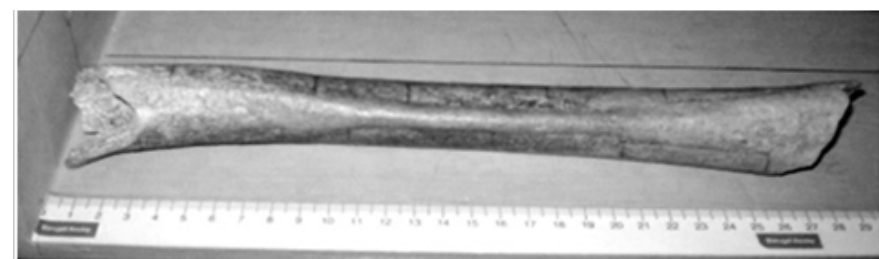

Figure 2 Specimen under study

The surface presents a homogenous white ivory color, with a great power of reflexion because of to the polishing (shinny), also its fracture edges present rounding because of to the polishing. ${ }^{37}$ Finally, there is an area of black-greenish color and half-grainy touch-sensitive in parts of the diaphysis suitable with incrustations of marine algae remains. The presence of gastropods, foraminifera and diatomeas, has confirmed that the bone was subject to marine environment. ${ }^{38,39}$ Although it is true that the color of the surface, state of conservation, the integrity of compact and trabecular tissues, it could be indicate that remain is a contemporary bone, the presence of poor medullary tissue in the diaphysis, make it difficult support this argument. ${ }^{40,41}$ The use of scanning electronic microscope (Fei Quanta 450 Model ()), using an direct analysis in high vacuum method (Energy Dispersive Spectrometry - EDX), allowed the proportion of nitrogen $(\mathrm{N})$ content in four samples (two of the medullary tissue and two samples of cortical tissue), showing values of between 1.44 and 1, 55 percent of nitrogen concentration, which, in principle, would move away from being a contemporary specimen $(4,5$ persent $){ }^{40}$ For bones with low protein, however, it would appear that collagen is being lost through a different process-such as chemically mediated hydrolysis. This may be because it is older and/or because most of the bones have been totally immersed in water. ${ }^{42}$

Studies on the concentration of nitrogen $(\mathrm{N}),{ }^{43-46}$ demonstrated that the levels will decrease with the passage of time. Decomposition of the bone results in a steady reduction in nitrogen content, although, as with previously described methods, humidity, exposure to air, and both the acidity and the temperature of the ambient environment alter this rate. We can't argue for the moment, how can affect marine water immersion to nitrogen concentration and quantity of loss medullary tissue. ${ }^{46,47}$ Finally, there would be an alternative hypothesis on the probable origin of the bone specimen. It is relatively common in Brazil to find human remains associated with Afro American rituals often in areas close to water courses. Many of these human remains are frequently stolen from modern or historical/archaeological cemeteries. Even in non-ritual cases, forensic anthropologists 
sometimes encounter remains unearthed from historic contexts (between five and eight percent of forensic anthropology cases or cemeteries (approximately seven percent of forensic anthropology cases. ${ }^{41,48}$

This argument could, in part, explain the good conservation of the diaphysis, and even the deterioration of the epiphyses. ${ }^{41}$ However, and beyond the interpretation of the post mortem interval, bone specimen under analysis (contemporary or historical/archaeological) show the absence of trampling traces. ${ }^{20,25,28,37,49,50}$ as well as the absence of traces produced by wind action ${ }^{29}$ and especially the presence of marine fauna, would aim at the direction on the origin of the traces produced by abrasion of marine sediments. The polished and shinny surface of the bone, prevented the correct observation of the alterations produced by the sedimentary abrasion. In order to evaluate the presence, density and spatial orientation of the abrasion prints over the surface of the bone, nine sample sectors were chosen located in different topographic locations of the bone, (proximal/medial/distal) in order to cover, in a representative way the surface of the bone, both the diaphysis and the ends of the meta-diaphysis. Each sample sectors of $1 \mathrm{x} 5 \mathrm{~cm}$, were subdivided likewise, in five rectangles of $1 \times 1 \mathrm{~cm}$ (Figure 3 ).

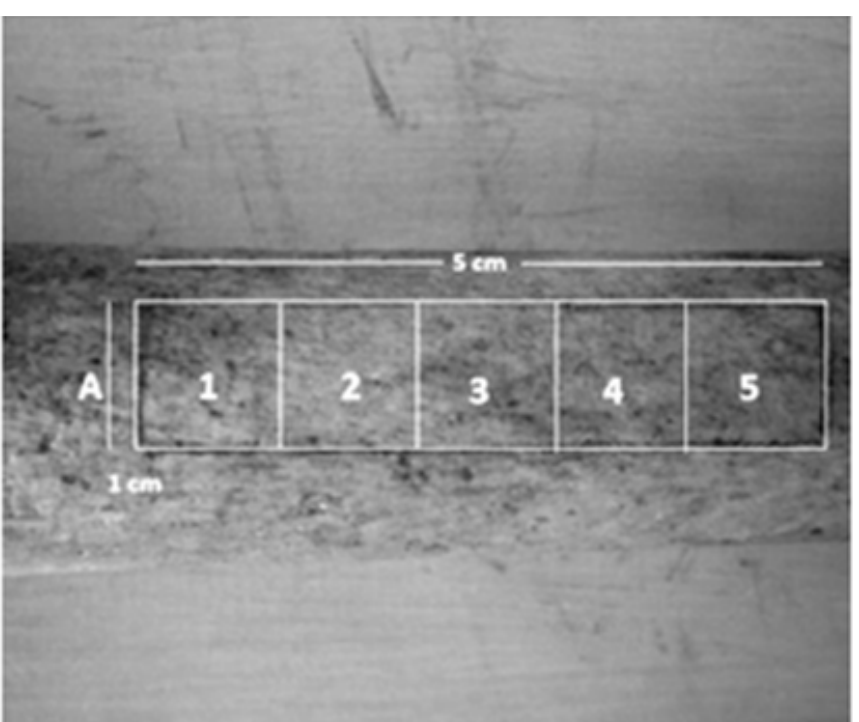

Figure 3 One of the nine sectors of sampling of $1 \times 5 \mathrm{~cm}$.

From a total of 45 rectangles of $1 \times 1 \mathrm{~cm}$ that represented the universe of observation, 25 rectangles were randomly selected. A total of 2.455 abrasion prints were collected identifying the following attributes: length, width, deepness and orientation. The utilization of a binocular loupe Leica, Mod.300® with optical digital camera Leica $\mathrm{EC} 3{ }^{\circledR}$ allowed the take of microphotography of each rectangle. The images obtained, were digitally processed in order to be qualitatively and quantitatively analyzed trough the package J.Microvision 2.7®. Finally, the numerical data relieved were put into Microsoft Excel ${ }^{\circledR}$ and were statisticalally analyzed with LXStat and were plotted through the platform VSN International GenStat $\mathbb{R}$ y Oriana 4.0.

\section{Abrasion}

The alteration of the surface of the bones is one of the most important points that have to be taken into account in the forensic context, since distinguishing the natural alterations from the cultural ones contributes to the reconstruction and interpretation of the forensic contexts. ${ }^{4,8}$ The abrasion is defined as the erosion of the surface of the bone by any agent through the physical force, ${ }^{51}$ this is characterized mostly by the rounding and polishing through the removal of the external bone tissue. ${ }^{52}$ Abrasion must not be confused with other phenomena such as acid erosion, which creates a rough surface of the bone ${ }^{51}$ The abrasion produces a rounding of the ends of the bone erasing details and giving the bone a polished look, although we can observe alterations at a microscopic level. . $^{5,9,51,53-55}$

There are many causes of abrasion both animal and human, ${ }^{4,56}$ such as the action of carnivores trough their digestion, ${ }^{57,58}$ the manufacturing and utilization of the bone as an instrument, bioturbation, ${ }^{59}$ transportation, ${ }^{26}$ and eolic action. ${ }^{60}$ The pioneer works of Brain $^{56}$ described the action of the abrasion over bones, not only as a consequence of human and animal stumping, but also as a consequence of power technology action. The author observed that the surface of the bones presented selective areas where they received the bombing of the sedimentary particles dragged by the wind ${ }^{28,56}$ The works of Behrensmeyer ${ }^{61}$ and Korth ${ }^{62}$ suggested that, also the fluvial transportation could produce erosion and abrasion over the surface of the bones. The observations of Boaz demonstrated that 67 over a total of 263 bones, had evidence of abrasion. These bones showed a deterioration of the cortical tissue, with exposure of the spongy tissue. $^{26}$

In consequence, if the abrasion is the removal of bone material caused by the impact of sedimentary particles,${ }^{60}$ the marine or fluvial abrasion, is the result of the direct and extended contact of the bone with the grains of sediment in water contexts. ${ }^{51}$ The transportation by water is one of the most important causes that produce abrasion. ${ }^{5,9,19,51}$ Some experiments about the abrasion carried forward by Korth, ${ }^{62}$ showed that the end of the bones turned more rounded and thinner. Shipman and Rose $^{60}$ give a list of the factors that produce abrasion by sediments. The size of the grains, the composition of the sedimentary particles, the presence/absence of soft parts or tissue in the bone, the conditions of the bone (fresh/weathered), the presence/absence of water in the sedimentary system and the direction and the distance of transportation. The most angled sediments, act with major impact in the abrasion of the bones, much more than the rounded sediments. ${ }^{62}$ The ends of the bone present more abrasion than the diaphysis, probably due to their volume., ${ }^{4}$

Recognizing the abrasion prints is just one side of the problem, as many processes produce this phenomena over the surface of the bones. Through the traces of trampling Brain, ${ }^{56}$ the technological product, ${ }^{60}$ and fluvial transportation, ${ }^{26}$ the distribution of the abrasion can be the key to distinguishing between the various agents. In the bones that were affected by the fluvial transportation, the entire surface appears affected. In the technological product, only area affected by abrasion would be the surface of the bones that are more exposed to outdoor conditions. On the other hand, the stumping can produce deep scratches on the surface of the bone unlike the fluvial erosion. ${ }^{25}$ The sole presence of elements that compose the same sedimentary matrix could indicate if it is marine or fluvial. Bromage ${ }^{51}$ reports a series of experiments to determine the alterations by abrasion but in a microscopic way. The abrasion can happen in pre-depositions, depositional, and post-depositional contexts. The abrasion with water and particles tends to produce a macroscopic shinny surface, (Figure 4) and suggests that the abrasion can be interceded by the elastic surface of the fresh bone absorbing part of the impact shock of the sand grains. ${ }^{37}$ This is of crucial importance because the bones in 
weathering stages 2 or 3 in the scale of Behrensmeyer, ${ }^{16}$ suffer more abrasive damage than those which are in stage 0 , therefore we must not forget this in any interpretation of the abrasion context. ${ }^{4,30}$

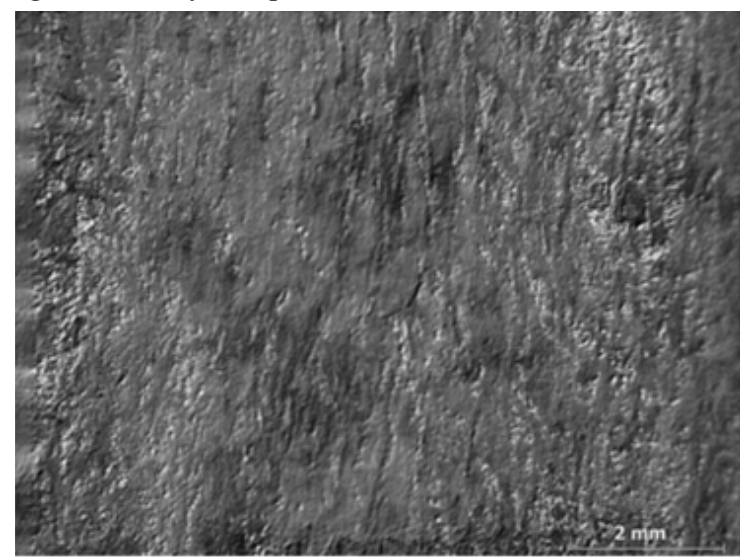

Figure 4 Photomicrograph of a sector of sampling $(\mathrm{IxI} \mathrm{cm})$. Observe the brightness of the surface subjected to abrasion.

\section{Abrasion by marine sediments}

Marine abrasion is the result of different movements of skeletal material and material that composes the marine substrate. ${ }^{9}$ The degree of abrasion has something to do with the energy of the environment, that is to say, the most intense erosion needs more energy, such as the waves and currents close to the coast. ${ }^{63}$ Some researchs studies, ${ }^{8,31,30}$ demonstrated that, in water mediums, more than fifty percent of the bones showed evidence of damage by the transportation of the water flow, nevertheless, little is known about its process of abrasion in those environments. In terms of the abrasion as indicating phenomena of the taphonomical history, it has been taken into account, not just the presence or absence of said abrasion, but also the major or minor abrasion, the utilization of the weathering stages of Behrensmeyer, ${ }^{16}$ or macroscopic comparative scales ${ }^{5}$ as to evaluate the damages. The small amount of investigation with macroscopic techniques of abrasion have found little correlation but clear differences between the patterns of alteration by abrasion and the type of bone, type of sediment and duration of the action.

Also the damages by abrasion depend on the elasticity of the bone; this will bring final differences in the taphonomical history. On the other hand, the tissues may have been removed as a result of the discomposure in the water, or before the exposure to water as a result of human or animal activity, this last subject is more relevant considering the possibility of funerary contexts in coastal areas. Although it is impossible for the moment to determine which of those scenarios the correct one is the presence of tissues has an important implication in the taphonomical history of a bone. ${ }^{34}$

\section{Results and interpretation}

The results demonstrated the presence of certain main types of abrasion traces: In first instance, all the bone has this polished surface, giving the shiny appearance. ${ }^{37}$ All fracture edges are round and polished surface, giving a fragile look to edge of the fracture line, but without affecting the structural integrity of the diaphysis of the bone. We have observed also, grooves. They present an average length of $1,78 \mathrm{~mm}$ an about $0,50 \mathrm{~mm}$ wide and an average depth of $0,50 \mathrm{~mm}$. The grooves are regular morphology and are mostly arranged in parallel to the major axis of the diaphysis of the bone. Other abrasive alterations with a different morphology were also identified, as ablations. ${ }^{51}$ These alterations are like flattened patches ${ }^{5}$ and have a length of $2,50 \mathrm{~mm}$ and are $0,70 \mathrm{~mm}$ wide and have an average deepness of $0,30 \mathrm{~mm}$ with more irregular shapes, and they are arranged longitudinally to the axis of the bone surface. At last holes, were identified, little hollows that appear isolated in the surface of the bone, with perimeters of $0,23 \mathrm{~mm}^{2}$ and deepness of 0,20mm (Table 1) and Figure 5.

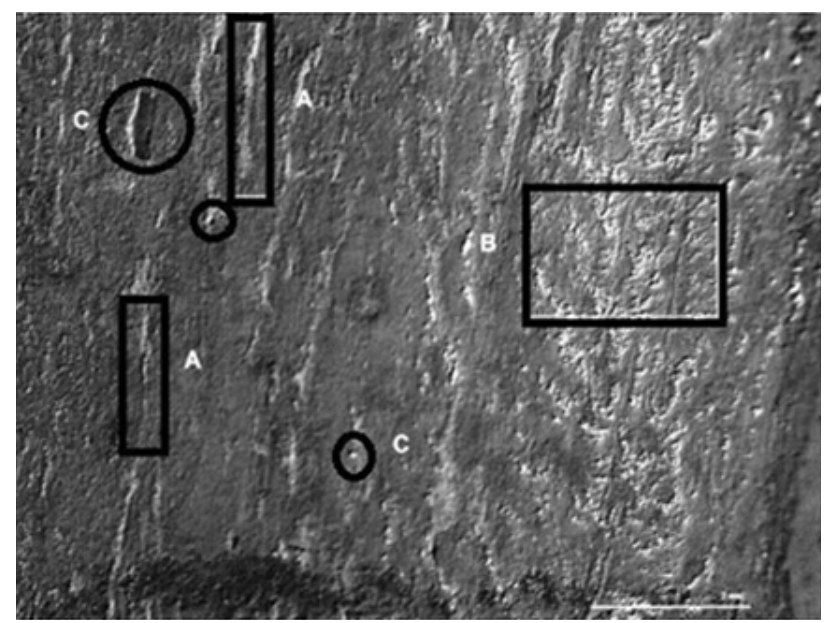

Figure 5 Image treated digitally showing grooves (A), ablation, (B) (flattened patches) and holes (C).

Table I Number $(\mathrm{N})$ and frequency $(\mathrm{f})$ of traces of abrasion sampled

\begin{tabular}{lll}
\hline Prints & Number & $\mathbf{f}$ \\
\hline Grooves & 1424 & 0.58 \\
Ablations & 843 & 0.34 \\
Holes & 188 & 0.07 \\
Total & 2455 & 100 \\
\hline
\end{tabular}

It is mostly assumed that the abrasion is a combination of phenomena related in a complex manner such as the type of sediment, the force of the liquid that transports these sediments and the state of the bone, (fresh, dry, weathered and fossilized), among other attributes. ${ }^{51}$ The main abrasive effects that the sediments in a liquid medium produce are: polishing and rounding of the ends and edges of the bone. It is important to take into account that type of bone when beginning the transportation sequence because each type of bone has a different resistance to abrasion. ${ }^{5}$ The weathered bone is rounded and it is polished faster, producing the detachment of slices that are not observed in the fresh bone. Also, we can observe the same phenomena in the fossil bone; both suffer more abrasion than the fresh and dry bone. It seems, the most resistant to the action of thin sand is the fresh bone. Outside the water the sedimentary abrasion is important in every type of bone. ${ }^{51}$

The pioneer model of Korth, ${ }^{62}$ already distinguished that the abrasion was produced, mostly by the action of small grains. Shipman and Rose $^{60}$ identified the same simulating the transportation and evaluating the abrasion in order to differentiate it from the signs of instruments over the surface of the bones. They both found that the small grains produce more abrasion. Each way of transportation results in different consequences of abrasion. The sediments are moving particles that depend on the flow of energy from nature. ${ }^{63}$ According 
to the velocity of the water flow the sediments move controlled also by the shape of the coast and topography of the ground. ${ }^{29,51}$ Basically they move basing on three models, that is to say, rolling through the marine ground, as the speed grows the sediments start to behave as missiles that jump over the surface of the marine ground. Finally, the greatest speed and force of the marine flow transports the sediments in a suspension way. The three models happen at the same time. ${ }^{9}$

According to the experimental results, ${ }^{5,9}$ the smaller grains, $(<$ $200 \mu \mathrm{m}-0.2 \mathrm{~mm})$, are the ones that produce more abrasion on the surface of the bones. In fresh and dry bones, once the superficial abrasion appears, the thin grains remove the external surface of the bone. The polishing degree of the bones was evaluated according to the brightness. The fresh and dry bones are the ones which produce more brightness, although all bones show an even brightness and polishing under thin sand. ${ }^{5}$ The beaches of the north coast of the Island of Santa Catarina, where the bone was found, present soil characteristics suitable with the alterations in the skeletal specimen. ${ }^{64}$ (Table 2) shows the results of geological soil survey formation of the beaches, as well as an evaluation of the size of the particles. It can be observed that the average of the grains $(0,175 \mathrm{~mm})$ is suitable with the dimensions of the damages produced to the bone. The low energy of the marine flows added to the little inclination of the beaches $\left(2^{\circ}\right),{ }^{64}$ stimulates the grouping of selective sediments of thin grains that acted over the specimen.

Table 2 Classification of the sandy sediments where the specimen was found ${ }^{63}$

\begin{tabular}{lll}
\hline Location & $\begin{array}{l}\text { Average diameter } \\
(\mathbf{m m})\end{array}$ & Granulometric type \\
\hline Canasvieiras (I) & 0,191 & Thin Sand \\
Canasvieiras (2) & 0,203 & Thin Sand \\
Canasvieiras (3) & 0,174 & Thin Sand \\
$\begin{array}{l}\text { Cachoeira do Bom } \\
\text { Jesus (I) }\end{array}$ & 0,195 & Thin Sand \\
$\begin{array}{l}\text { Cachoeira do Bom } \\
\text { Jesus (2) }\end{array}$ & 0,182 & Thin Sand \\
$\begin{array}{l}\text { Cachoeira do Bom } \\
\text { Jesus (3) }\end{array}$ & 0,174 & Thin Sand \\
$\begin{array}{l}\text { Ponta das Canas (I) } \\
\text { Ponta das Canas (2) }\end{array}$ & 0,202 & Thin Sand \\
$\begin{array}{l}\text { Prainha de Ponta das } \\
\text { Canas }\end{array}$ & 0,188 & Thin Sand \\
\hline
\end{tabular}

The grooves were produced by the sediments rolling through the marine ground, meanwhile as the velocity grows the sediments behave like missiles that jump over the surface of the marine ground producing the alteration of the surface of the bone and expanding, in some cases, the pre-existing abrasions, (grooves), producing the ablation of the periosteal and creating areas of elongated and irregular shape that are the flattened patches. The sediments transported in suspension, that is to say, the transportation related to higher levels of energy, are the ones that may be producing the holes. As for the micro-grooves, these also could be produced by the thin sediments involved in marine movements in suspension, ${ }^{9}$ related to episodes of more energy, producing prints of little deepness and oriented in a random way along the bone. This hypothesis will have to be opposed through the Scanning Electronic Microscope, information that will be completed later in another work.

\section{Statistical analysis}

Using quantitative statistical analysis, try to check that the traces of abrasion would present an orientation of anisotropic type, i.e. not at random. To prove if one is random (isotropic) or non-random (anisotropic) orientation, we use the non-parametric test of distribution circular base of Kuiper data $(V)$ and Watson test (U2) [65]. Finally, for the evaluation of the normal distribution of the circular data we use the Von Mises distribution and uniformity data test $(R)$ of Rayleigh. For this, the dispersion is quantified by a parameter $k$ concentration, where $k=0$ corresponds to an isotropic distribution and the values in increasing order reflect a tendency to anisotropy. (Table 3) shows that the statistical results support a model of special nature anisotropic distribution of the traces. The Rayleigh $(R)$, Kuiper $(V)$ and Watson $(U 2)$ tests would support in a significant way $(\mathrm{p}<0.05)$ that the group of traces would show a strong preferential orientation no matter the surface of the bone where the sample was taken. When we consider the orientation of the abrasion traces, we observe a constant vector coincident with the major axis of the bone with not very significant values of circular variance. This could reflect that this preferential type of orientation of the abrasion traces would also indicate the predominant orientation of the bone in a liquid medium, Figure 6. In a distribution of isotropic nature, the direction of the abrasion prints would be random all over the surface. In an anisotropic distribution, the direction of the prints presents and even orientation of non-random nature.

Table 3 Concentration values, mean direction, basic statistics and omnibus tests of the total sampled traces

\begin{tabular}{|c|c|}
\hline Attribute & Grooves sample area \\
\hline Data Type & Angles \\
\hline Number of Observations & 1424 \\
\hline Data Grouped? & No \\
\hline Mean Vector $(\mu)$ & $15,816^{\circ}$ \\
\hline Length of Mean Vector ( $r$ ) & 0,911 \\
\hline Median & $8^{\circ}$ \\
\hline Concentration & 5,935 \\
\hline Circular Variance & 0,089 \\
\hline Circular Standard Deviation & $24,668^{\circ}$ \\
\hline Standard Error of Mean & $1,478^{\circ}$ \\
\hline Rayleigh Test (Z) & 230,963 \\
\hline Rayleigh Test (p) & 0.000012 \\
\hline Rao's Spacing Test (U) & 326,46 \\
\hline Rao's Spacing Test ( $\mathrm{p}$ ) & $<0.01$ \\
\hline Watson's U² Test (von Mises, $U^{2}$ ) & 13,957 \\
\hline Watson's U² Test (p) & $<0.005$ \\
\hline Kuiper's Test (von Mises,V) & 13,303 \\
\hline Kuiper's Test ( $p)$ & $<0.01$ \\
\hline
\end{tabular}




\section{Sector I}

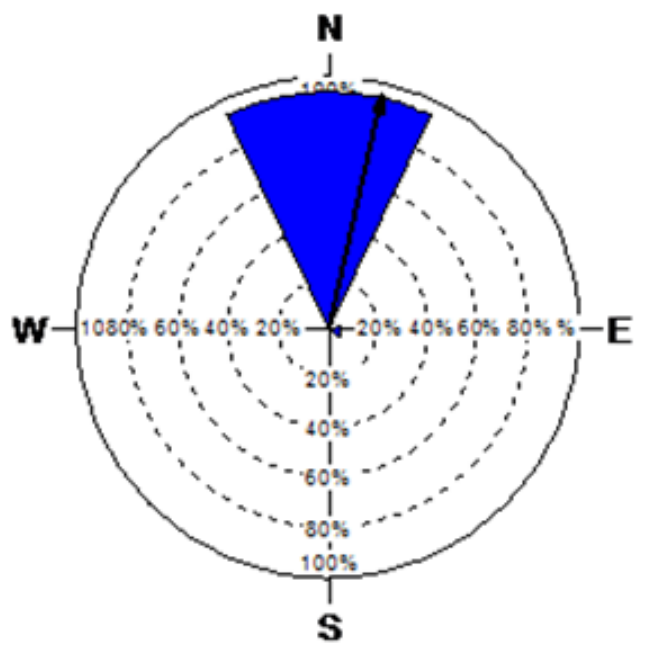

Figure 6 Rose Diagram of the traces abrasion sample with histograms of preferred orientation.

The experimental studies about the average orientation of the bones subject to currents of water flow, have demonstrated a high correlation between the major length of the bone and the flow current. These results would support our observation as to a high correlation between the direction of the grooves and the major length of the diaphysis. ${ }^{5,9}$ Three main factors control abrasion in unidirectional water movements: the amount of water involved, bone morphology (i.e. taxon, texture of the bone surface), skeletal element, anatomical landmark and the state of preservation of the periosteum. The presence of periosteum is crucial, because it is the first tissue affected by abrasion and it protects both the underlying tissue and also the overall morphology and the bone surface against abrasive alterations and damage. In unidirectional water movement the degree of abrasion is governed by the amount of water involved. Tumbling in dry sediment caused heavy abrasion whereas abrasion decreases with increased volume of water. $^{66}$ Abrasion affected the remaining periosteum, the outer bone surface as well as the overall bone morphology. In addition abrasion produced bone-surface modifications that differed distinctively in settings mimicking uni- and multidirectional water movements respectively.

\section{Conclusion}

The abrasive effects of the particles were strong enough to eliminate the bone tissue and alter the morphology of the periostium. ${ }^{67}$ The exposure of a bone to a marine environment includes the action of sediment particles in an energetic medium, being able to crucially alter the morphology of the surface of the bone. A series of abrasion traces by marine sediments have been identified. The abrasion produced by the smaller sediments (thin sediments), $<0,2$ $\mathrm{mm}$, would produce prints (grooves) parallel to the longitudinal axis of the bone. These abrasions would be related with water movements of low energy. The abrasion due to the increase of the energy and the impact of the sedimentary particles would produce the abrasion of the grooves and the cortex of the periostium producing an expansion of the abrasion surface resulting in the presence of more irregular structures that are flattened patches. The holes are witnesses of the impact of the sediments, probably in situations of increase of water energy and, above all, of sediments in suspension. The prevailing orientation of the specimen in the marine ground all along its main axis (diaphysis), due to the shape of it, and mainly by the water flow (current), is the reason that the grooves and the flattened patches have an orientation of anisotropic nature, that is to say with an orientation in a non-random direction. Nevertheless, the presence of diatomaceous (Cymatopleurasolea y Naviculalanceolata) as well as shells attached in the periostium, would indicate prevailing sequences of extended immersion in low energy environments. ${ }^{35}$

The orientation of the skeletal material plays an important role in the interpretation of the taphonomic formation processes. Experimental studies have evaluated the orientation of a bone sample subject to the action of water. The results demonstrate significant similarities according to the shape of the bone (development of the optimum shape) according to the symmetrical longitudinal axis is one of the best structures in the same direction of the wind and the water. ${ }^{52,65}$ Although the action between these attributes was already quoted, any contribution is important for that matter. For the archeological and dry bones, the major alteration is by dragging in the marine ground producing ablation (flatetened patches) and cracks. For fresh bone during saltation, ablation, cracking and pitting. ${ }^{9,68}$ The results of this study have demonstrated that the groovesand flattened patches present the same orientation and are indicators, of the direction of the current and of the position of the bone within the water flow, due to the geometric shape of the major axis (diaphysis). Probably the microgrooves present great variety and standard deviation, since they behave in a random way like the sediments in suspension. But this argument should be tested.

The implications of these results can provide valuable information in the determination of the length of time that the skeletal material has been subject to a certain environment. ${ }^{9,69}$ It is clear that it is necessary a deeper work to evaluate the way in which the transportation of sediments interacts, the shape of the marine ground, and even the shape and size of the sedimentary particles. Although there is very little information about the impact that the aquatic marine environment imposes to the bones, the experimental trials and the observations over human remains recovered from the marine environment, are valuable contributions, from the diagnosing point of view, as we can count with the presence of solid indicators that support our argument about the taphonomical history of the skeletal remains. ${ }^{9,51}$

\section{Acknowledgments}

None.

\section{Funding}

None.

\section{Conflicts of interest}

The authors declare there is no conflicts of interests.

\section{References}

1. Pokines JT, Symes SA. Marine Environmental Alterations to Bone. Manual of forensic Taphonomy, USA: CRC Press; 2013:143-180.

2. Raton A, Taylor E, Francis E. Mediterranean 'becoming a cemetery'. Europe: BBC News Europe; 2014. 
3. Nawrock SP, Pless J, Hawley D, et al. Fluvial transport of human crania In: Haglund W, Sorg M, editors. Forensic Taphonomy: The Postmortem Fate of Human Remains, USA: CRC Press; 1997:529-552.

4. Lyman RL. Vertebrate taphonomy. UK: Cambridge University Press; 1994:1-524.

5. Fernandez-Jalvo Y, Andrews P. Experimental Effects of Water Abrasion on Bone Fragments. Journal of Taphonomy. 2003;1(3):147-163.

6. Haglund W, Sorg M. Forensic taphonomy: the post-mortem fate of human remains. In: Haglund W, Sorg M, editors. USA: CRC Press; 1997:1-636.

7. Bell LS, Elkerton A. Human remains recovered from a sixteenth century mass fatality: unique marine taphonomy in human skeletal materia from the medieval warship the Mary Rose. International Journal of Osteoarchaeology. 2008;18:523e-535e.

8. Haglund WD. Disappearance of soft tissue and the disarticulation of human remains from aqueous environments. Journal of Forensic Sciences. 1993;38(4):806e-815e.

9. Thompson CS, Ball TJU, Thompson D, et al. The abrasion of modern and archaeological bones by mobile sediments: the importance of transport modes. Journal of Archaeological Science. 2011;38:784-793.

10. Bassett HE, Manhein MH. Fluvial transport of human remains in the Lower Mississippi River. Journal of Forensic Sciences. 2002;47(4):719724.

11. Nasti A. Amigos son los amigos. 'Ajuar funerario o visitante intrusivo'. Observaciones Tafonomicas sobre restos de Canis sp. Asociados con restos humanos. Revista de Arqueología Americana. 2012;29:100-117.

12. Dirkmaat DC, Cabo LL, Ousley SD, et al. New perspectivesin forensic anthropology. Am J Phys Anthropol. 2008;(Suppl 47):33-52.

13. Nasti A. Modification of Vicuña Carcases in High-Altitude Desert 1. Current Anthropology. 2008;41(2):1-3.

14. Nasti A. Dragging and scattering to Lama sp. bones for fluvial action in the Real Grande gorge (Province of Catamarca, Argentina Meridional Puna). Journal of Taphonomy. 2005;3(4):175-185.

15. Nasti A. Expandiendo el rol de la arqueología: Nuevas perspectivas en Tafonomia Forense. 2008:1-7.

16. Behrensmeyer AK. Taphonomic and ecologic information from bone weathering. Paleobiology. 1978;4(2):150-162.

17. Hockett BS. Corroded, Thinned and Polished Bones Created by Golden Eagles (Aquila chrysaetos): Taphonomic Implications for Archaeological Interpretations. Journal of Archaeological Science. 1996;23(4):587-591.

18. De Battista R, Thompson TJ, Thompson CE, et al. A comparison of surface features on submerged and non-submerged bone using scanning electron microscopy. Journal of forensic and legal medicine. 2013;20(6):770-776.

19. Nicholson RA. Bone Degradation, Burial Medium, and Species Representation. Journal of Archaeological Science. 1996;23(4):513-533.

20. Andrews P. Experiments in taphonomy. J Archaeol Sci. 1995;22:147-153.

21. Andrews P, Whybrow P. Taphonomic observations on a camel skeleton in a desert environment in Abu Dhabi. Palaeontologia Electronica. 2005;8(1):1-17

22. Todisco $\mathrm{D}$, Monchot $\mathrm{H}$. Bone weathering in a periglacial environment: the tayara site (KbFk-7), Qikirtaq Island, Nunavik (Canada). 2008;61(1):87101.

23. Andrews P, Cook J. Natural modifications to bones in a temperate setting. Man. 1985;20(4):675-691.
24. Morris P. Bone weathering in the mediterranean climate of the northern california foothills: a taphonomy study. Thesis. USA: California State University; 2013:1-170.

25. Behrensmeyer AK, Gordon KD, Yanagi GT. Trampling as a cause of bone surface damage and pseudo-cutmarks. Nature. 1986;319:768-771.

26. Boaz NT, Behrensmeyer AK. Hominid taphonomy: transport of human skeletal parts in an artificial fluviatile environment. Am J Phys Anthropol. 1976;45(1):53-60.

27. Bonnichsen R, Sorg MH. Bone modification. Center for the study of the first Americans, USA: University of Maine; 1989:1-535.

28. Olsen SL, Shipman P. Surface modification on bone: trampling versus butchery. J Archeol Sci. 1988;15:535-553.

29. Shipman P. Life history of a fossil. USA: Harvard University Press; 1981.

30. Littleton J. Taphonomic effects of erosion on deliberately buried bodies Journal of Archaeological Science. 2000;27:5-18.

31. Kahana T, Almog J, Shmeltzer E, et al. Marine taphonomy: adipocere formation in a series of bodies recovered from a single shipwreck. $J$ Forensic Sci. 1999;44(5):897e-901e.

32. Barrientos G, Patricia L, Sarmiento E, et al. Evaluación de la diagénesis ósea mediante el uso de microscopia electrónica de barrido (MEB): Aproximaciones aplicables a muestras arqueológicas. Revista Argentina de Antropología Biológica. 2016;18(2):1-14.

33. Alberdi M, Alonso MA, Azanza B, et al. Vertebrate taphonomy in circum-lake environments: three cases in the Guadic-Baza Basin (Granada, Spain). Palaeogeography, Palaeoclimatology, Palaeoecology. 2001;165(1-2):165-187.

34. Coard R. One bone, two bones, wet bones, dry bones: transport potentials under experimental conditions. Journal of Archaeological Science. $1999 ; 26: 1369 \mathrm{e}-1375 \mathrm{e}$.

35. Delabarde T, Keyser C Tracqui A, et al. The potential of forensic analysis on human bones found in riverine environment. Forensic Sci Int. 2013;228(1-3):e1-15.

36. Halling Ch, Nawrocki S, Gibbs S. Fluvial Transport of Human Remains at Actun Tunichil Muknal, Belize. USA: University of Indianapolis; 2000.

37. Madgwick R. What makes bones shiny? Investigating trampling as a cause of bone abrasión. Archaeological and Anthropological Sciences. 2014;6(2):163-173

38. Bell L, Elkerton A. Unique marine taphonomy in human skeletal material recovered from the medieval warship mary rose. International Journal of Osteoarchaeology. 2007;18(5):523-535.

39. Pokines J, Nicholas Higgs. Macroscopic taphonomic alterations to human bone recovered from marine environments. Journal of Forensic Identification. 2012;65(6):1-953.

40. Swift B. The timing of death in essentials of autopsy practice 10. In: Rutty GN, editor. Current Methods and Modern Trends, UK: Springer; 2006:189-214.

41. Pokines JT, Zinni DP, Crowley K. Taphonomic patterning of cemetery remains. received at the office of the chief medical examiner, boston, massachusetts. J Forensic Sci. 2016;61(Suppl 1):71-81.

42. Nielsen MC, Hedges Robert EM. Patterns of diagenesis in bone i: the effects of site environments. Journal of Archaeological Science. 2000;27(12):1139-1150.

43. Knight B. Estimation of the time since death: a survey of practical methods. Journal of the Forensic Science Society. 1968;8(2-3):91-96. 
44. Knight B, Lauder I. Practical methods of dating skeletal remains: a preliminary study. Med Sci Law. 1967;7(4):205-208.

45. Knight B, Lauder I. Methods of dating skeletal remains. Hum Biol. 1969;41(3):322-341.

46. Jarvis DR. Nitrogen levels in long bones from coffin burials interred for periods of 26-90 Years. Forensic Sci Int. 1997;85(3):199-208.

47. Winburn A. Afro-Cuban ritual use of human remains: medicolegal considerations. Journal of Forensic Identification. 2017.

48. Hedges R, Millard R. Bones and groundwater: towards the modelling of diagenetic processes. Journal of Archaeological Science. 1995;22:155164 .

49. Nielsen AE. Trampling the archaeological record: an experimentalstudy. Am Antiq. 1991;56(3):483-503.

50. Bromage TG. Interpretation of scanning electron microscopic images of abraded forming bone surfaces. Am J Phys Anthropol. 1984;64(2):161178 .

51. Behrensmeyer AK. Time resolution in fluvial vertebrate assemblages. Paleobiology. 1982;8(3):211-227.

52. Behrensmeyer AK. Vertebrate preservation in fluvial channels Palaeogeography and Palaeoclimatology. 1988;63:183-199.

53. Behrensmeyer AK. Bones. In: Briggs DEG, Crowther PR, editors. Palaeobiology: a synthesis. USA: Blackwell Scientific; 1990:232-235.

54. Pinto Llona AC, Andrews PJ. Amphibian taphonomy and its application to the fossil record of Dolina (middle Pleistocene, Atapuerca, Spain) Palaeogeogr Palaeoclimatol. 1999;149:411-429.

55. Brain CK. The hunters or the hunted? An introduction to African cave taphonomy. USA: University of Chicago Press; 1981.

56. Andrews P, Owls A. Caves and fossils: predation, preservation and accumulation of small mammal bones in caves, with an analysis of the pleistocene cave faunas from Westbury-Sub-Mendip, Somerset, USA; 1990:1-231.

57. Haynes G, Stanford D. On the possible utilisation of Camelops by early man in North America. Quat Res. 1984;22(2):216-230.
58. Haynes G. Evidence of carnivore gnawing on Pleistocene and recent mammalian bones. Paleobiology. 1980;6(3):341-351.

59. Shipman P, Rose JJ. Bone tools: an experimental approach. Scanning Electron Microscopy in Archaelogy. British Archaeological Reports International Series. 1988;452:303-335.

60. Behresnsmeyer A. The taphonomy and paleoecology of Plio-Pleistocene vertebrate assemblages east of Lake Rudolf, Kenya. USA: Harvard University; 1975:1-146.

61. Korth WW. Taphonomy of microvertebrate fossil assemblages. Annals of the Carnegie Museum. 1979;48:235-285.

62. Driscoll EG, Weltin TP. Sedimentary parameters as factors in abrasive shell reduction. Palaeogeography, Palaeoclimatology, Palaeoecology. 1973;13:275-288.

63. Oliveira UR, Parizotto BA, Horn NO, et al. Setorizacao Morfossedimentar das praias arenosas da ilha deSanta Catarina (SC) Utilizando técnicas de analiseestatistica multivariada. Dezembro. 2012;10(1):1-11.

64. Dominguez-Rodrigo M, Garcia Perez A. Testing the accuracy of different a-axis types for measuring the orientation of bones in the archaeological and paleontological record. PLoS One. 2013;8(7):68955.

65. Windheuser SG, Kindler L, Rabinovich R, et al. Testing heterogeneity in faunal assemblages from archaeological sites. Tumbling and trampling experiments at the early-Middle Pleistocene site of Gesher Benot Ya'aqov (Israel). Journal of Archaeological Science. 2010;37:3170-3190.

66. Appleton A. The effects of particulate-laden water on skeletal trauma. department of forensic science/ forensic science \& pre-medical biology. USA: Christopher OR; 2014.

67. Madgwick R, Broderick L. Taphonomies of trajectory: the pre- and postdepositional movement of bones. Archaeol Anthropol Sci. 2015;8(2):223226.

68. Haglund WD, Sorg MH. Introduction to forensic taphonomy. In: Haglund WD, Sorg $\mathrm{MH}$, editors. Forensic taphonomy: the postmortem fate of human remains. USA: CRC Press; 1997:1-9.

69. Hedges R, Millard AR. Measurements and relationships of digenetic alteration of bone from three archaeological sites. Journal of Archaeological Science. 1995;22:201-209. 